\title{
RE: Correspondence: Isometric handgrip exercise training reduces resting systolic blood pressure but does not interfere with diastolic blood pressure or heart rate variability in hypertensive subjects: a systematic review and meta-analysis of randomized clinical trials
}

\author{
Neil A. Smart ${ }^{1}$ \\ Received: 6 January 2022 / Accepted: 11 January 2022 / Published online: 4 March 2022 \\ (c) The Author(s), under exclusive licence to The Japanese Society of Hypertension 2022
}

\section{Dear Editor,}

I wish to bring to your attention several methodological concerns regarding the systematic review and meta-analysis conducted by Almeida et al. 2021 published in Hypertension Research in September 2021. In essence, I believe that the work does not reflect the published works stipulated in the inclusion and exclusion criteria by the authors. Specifically, I make the following assertions:

1. One study, Millar et al. [1], was incorrectly included in this review, as this article clearly states (Page 621) that subjects were allocated on a 'nonrandomized cohort design". This fact has been verified via direct communication with the primary author. Almeida et al. stated that 'randomized clinical trials' were the study design necessary for inclusion.

2. Other included studies reported on participants who did not meet the inclusion criteria of 'treated hypertensives'. Badrov et al. [2] only had $83 \%$ of medicated participants, in Taylor et al. [3] 'most' but not all participants were medicated.

3. I believe the authors failed to identify the study by Farah et al. [4] and that this study should have been included.

4. I also believe that the study by Okamoto et al. [5] was also not identified and should have been included even though participants were unmedicated, based upon the prior inclusion of the studies by Badrov 2013 and Taylor 2003, who also reported data from unmedicated participants.

Neil A. Smart

nsmart2@une.edu.au

1 School of Science \& Technology, University of New England, Armidale, NSW 2350, Australia
Collectively, I believe these inconsistencies suggest that Almeida's work does not accurately represent the published literature according to the scope of work identified from their inclusion and exclusion criteria. Furthermore, I ascertained, from pooled analyses, that if the correct inclusion criteria were applied, a statistically significant and clinically meaningful reduction in diastolic blood pressure, of the order of $-3.2 \mathrm{mmHg}$, would have been observed.

Kind regards

Neil A. Smart

\section{Compliance with ethical standards}

Conflict of interest The author declares no competing interests.

Publisher's note Springer Nature remains neutral with regard to jurisdictional claims in published maps and institutional affiliations.

\section{References}

1. Millar PJ, Levy AS, McGowan CL, McCartney N, MacDonald MJ. Isometric handgrip training lowers blood pressure and increases heart rate complexity in medicated hypertensive patients. Scand J Med Sci Sports. 2013;23:620-6.

2. Badrov MB, Horton S, Millar PJ, McGowan CL. Cardiovascular stress reactivity tasks successfully predict the hypotensive response of isometric handgrip training in hypertensives. Psychophysiology. 2013;50:407-14.

3. Taylor AC, McCartney N, Kamath MV, Wiley RL. Isometric training lowers resting blood pressure and modulates autonomic control. Med Sci Sports Exerc. 2003;35:251-6.

4. Farah BQ, Rodrigues SLC, Silva GO, Pedrosa RP, Correia MA, Barros MVG, et al. Supervised, but not home-based, isometric training improves brachial and central blood pressure in medicated hypertensive patients: a randomized controlled trial. Front Physiol. 2018;9 961.

5. Okamoto T, Hashimoto $\mathrm{Y}$, Kobayashi R. Isometric handgrip training reduces blood pressure and wave reflections in East Asian, nonmedicated, middle-aged and older adults: a randomized control trial. Aging Clin Exp Res. 2020;32:1485-91. 